\title{
QUANTIFICATION OF MINOR TEXTURE COMPONENTS BY HARD X-RAYS
}

\author{
H.F. POULSEN ${ }^{\mathrm{a}, *}$, D. JUUL JENSEN ${ }^{\mathrm{a}}$, T. TSCHENTSCHER ${ }^{\mathrm{b}}$, \\ L. WCISLAK ${ }^{\text {b }}$, E.M. LAURIDSEN ${ }^{\mathrm{a}}$, L. MARGULIES ${ }^{\mathrm{a}, \mathrm{c}}$ \\ and S. SCHMIDT ${ }^{\mathrm{a}}$
}

${ }^{a}$ Materials Research Department, Risø Nat. Lab., DK-4000 Roskilde, Denmark;

${ }^{\mathrm{b}}$ HASYLAB at DESY, Notkestrasse 85, D-22607 Hamburg, Germany;

${ }^{\mathrm{c}}$ European Synchrotron Radiation Facility, BP 220, F-38043 Grenoble, France

(Received 3 May 2001; In final form 25 May 2001)

Non-destructive methods to determine the volume fraction of minor texture components with very low reflection intensities are presented. The methods are based on polycrystalline diffraction of hard X-rays from synchrotron sources. By focusing the X-rays and scanning the specimen, it is shown that volume fractions as low as $10^{-9}$ can be registered, provided that the crystallographic orientations of such volume elements are far away from any major texture component. Simultaneously, the spatial resolving power is of the order $0.03 \mu \mathrm{m}^{3}$. The relevance of such methods for nucleation studies and trace analysis is outlined.

Keywords: Synchrotron hard X-rays; Texture analysis; Minor texture components; Nucleation; Orientation analysis; Single crystal; Polycrystalline matter

\section{INTRODUCTION}

In most texture studies focus is on the major texture components. This is an obvious choice because the properties of a material are dominated by these components and because they can be used to

*Corresponding author. E-mail: henning.friis.poulsen@risoe.dk 
interpret the main structural changes occurring during processing. However, in certain cases also the minor texture components are of interest. For example, when testing texture models. An advanced model can normally not only predict the development of the major texture component, but also the minor ones and it is these latter ones which, generally, are most sensitive to the modelling parameters and assumptions.

Another example is nucleation within the context of phase transformation or recrystallization. Here the requirements for the sensitivity of the method (i.e. detection of very low volume fractions) and the resolving power of the instrument are extremely high. As an example, a key issue in recrystallization is how the nuclei develop and with what orientations relative to the site where they are formed. At present, the most common opinion is that the nuclei develop by simple growth of some specific cells or subgrains already present in the deformed microstructure. Experimental findings (e.g. Humphreys and Hatherly, 1995) and proposed models (Humphreys, 1997) support this opinion. So do the classical nucleation mechanism models including nucleation by coalescence $(\mathrm{Hu}, 1963)$ and by strain induced boundary migration (Beck and Sperry, 1950) as well as nucleation in transition bands (Dillamore et al., 1972) and cube nucleation in cube bands (e.g. Doherty et al., 1995 and Zaefferer et al., 2001). There are, however, also publications which report on development of nuclei with orientations different from those observed in the deformed microstructure (e.g. Kikuchi et al., 1992, Kamijo et al., 1993, Godfrey et al., 1995, Inoko et al., 1995, Kashiara et al., 1996, Huang et al., 2000). In the latter case, a concern is always if the characterization of the orientations in the deformed state has been detailed and precise enough and if a sufficient sample volume has been included in the observation. Typically all cells within a volume of $10^{-3}-1 \mathrm{~mm}^{3}$ must be registered. As the cells have volumes of the order $0.03-1 \mu \mathrm{m}^{3}$, volume fractions $V_{v}$ of the order $10^{-6}-10^{-9}$ have to be quantified.

With standard techniques it is problematic, if not impossible, to measure such low volume fractions. Typical pole figure constructing techniques with conventional laboratory X-ray texture diffractometers are limited by the determination of the proper background levels and by peak defocusing issues. The electron back scattering pattern 
(EBSP) technique in the scanning electron microscope (SEM) is limited by the spatial resolution, which, except for the field emission gun (FEG), SEMs are of the order of $0.5-1 \mu \mathrm{m}$ (Humphreys and Brough, 1999) and by the total sample area covered. Even with the most modern automatic scanning techniques, it takes about $0.25 \mathrm{~s}$ per pattern and it would thus take about 8 years of uninterrupted measurement time to find the one cell or subgrain out of a billion with a special orientation (i.e. $V_{V}=10^{-9}$ ). Furthermore, if automatic "cleaning-up procedures" are applied to avoid "bad data points", this one orientation might well be omitted and be only seen as a black spot in the orientation micrographs (Juul Jensen, 2000). Transmission electron microscope (TEM) based techniques offer sufficient spatial resolution for the detailed characterization of the deformed microstructure but, of course, suffer even more than the EBSP technique by the limited sample area covered.

Another concern is that the standard measuring techniques all probe the sample surface. The dynamics of the microstructure on the surface is not representative of bulk behavior due to phenomena such as pinning, atypical grain growth, migration of dislocations and stress release. Hence, with a destructive technique it is not possible within the bulk of the material to identify which of the cells or subgrains in a map of the deformed structure that actually is going to nucleate. Likewise, if a new grain is identified in the microstructure there is no way to determine the deformed structure at the same site prior to the nucleation.

The aim of the present work is to present two non-destructive methods for bulk pole figure determination by means of hard X-rays and discuss their potential for quantification of the volume fraction of minor texture components with very low diffraction intensities. The work was performed at two synchrotron sources. First, a standard pole figure over a gauge volume of $4 \times 1 \times 1 \mathrm{~mm}^{3}$ was generated at HASYLAB. Next, so-called high resolution pole figures were determined at the recently developed 3-Dimensional X-Ray Diffraction (3DXRD) microscope at ESRF. In this case the gauge volume was $10 \times 8 \times 1000 \mu \mathrm{m}^{3}$. By scanning the sample and determining high resolution pole figures at each position we show how it is possible within 1 day to probe a total volume of $0.05 \mathrm{~mm}^{3}$ with a spatial resolving power of $0.03 \mu \mathrm{m}^{3}$. 
The study was performed on an aluminium single crystal of a stable initial orientation deformed to $\varepsilon=1.5$ and recovered at room temperature for a long period (several years). This ensures that the texture is very simple, containing only one major texture component with a certain spread, and that the texture does not change between the two types of synchrotron experiments.

\section{SAMPLE}

The sample used for the investigation was prepared from a single crystal of $99.993 \%$ pure aluminium of the S-orientation $\{123\}\langle 634\rangle$. The crystal was channel die deformed to a strain of $\varepsilon=1.5$ at room temperature using a teflon film lubricant (Orlans-Joliet et al., 1990). The deformation microstructure and annealing response of this sample was investigated in detail (Godfrey et al., 2001). It was found that the deformation microstructure consists of a regular microband structure broken up by narrow regions of localized shearing. TEM Kikuchi and EBSP investigations revealed an average misorientation between neighboring cells of about $3^{\circ}$ with peak misorientation angles up to $16^{\circ}$. The TEM orientation measurements showed no observable difference between the regions with regular microband structure and the localized shearing. In both regions the cell structure is elongated along the band direction with significant variations from region to region. The dimensions of the cells as observed in the RD-ND plane typically is in the range $0.2-1.5 \mu \mathrm{m}$ and $0.6-3.5 \mu \mathrm{m}$ in the short and long direction, respectively. The average cell volume is estimated to be $0.5 \mu \mathrm{m}^{3}$.

For the present synchrotron experiments a sample with the dimensions $3.9 \times 0.8 \times 1.2 \mathrm{~mm}^{3}$ along $\mathrm{RD}$, TD and ND, respectively, was cut with a slow speed saw. In between the two synchrotron experiments, the EBSP technique was used to map the orientations present in the sample. 17000 orientations were measured on a polished surface using a mesh step of $10 \mu \mathrm{m}$. The result is shown in Fig. 1. In the plot only data with more than 5 out of 8 lines correctly indexed are included. As expected, the sample exhibits a spread S-texture. The spread is comparable to that found by Godfrey et al. (2001) on a freshly deformed sample. No orientations away from the main poles are observed. 


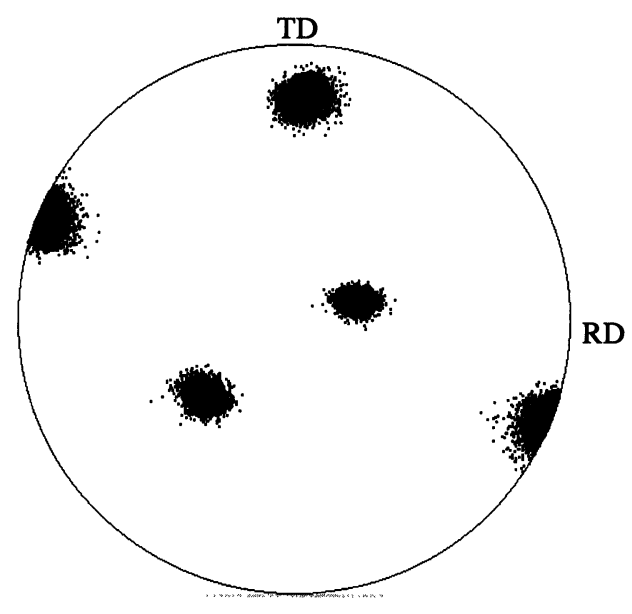

FIGURE 1 The (111) pole figure generated by EBSP on the surface of the $\varepsilon=1.5$ deformed $\mathrm{Al}$ single crystal. The 17000 orientations were measured in a grid with a step size of $10 \mu \mathrm{m}$. Only data with more than 5 out of 8 lines correctly indexed are included in the figure (Krieger Lassen et al., 1992).

\section{STANDARD HARD X-RAY POLE FIGURE}

The first experiment was performed at the high-energy beamline BW5 at HASYLAB in Hamburg (Bouchard et al., 1998). Here a dedicated set-up for bulk texture measurements has been established (see e.g. Poulsen et al., 1998, Mishin et al., 2000, Wcislak et al., 2001). A monochromatic beam with an energy of $100 \mathrm{keV}(\lambda=0.124 \AA)$ was produced by a broadband $\mathrm{Si} / \mathrm{Ge}$ gradient monochromator (Keitel et al., 1998). The texture set-up is sketched in Fig. 2. The incident beam was defined by a slit to be $1 \times 1 \mathrm{~mm}^{2}$, impinging on the center of the sample. The sample was mounted on a horizontal rotation table ( $\omega$ - rotation) with TD along the $\omega$-axis and RD parallel to the beam for $\omega=0^{\circ}$. The diffracted beam was transmitted through the sample with virtually no absorption, as the penetration depth in aluminum is $40 \mathrm{~mm}$ at $100 \mathrm{keV}$. The detector was an online MAR345 Image Plate Scanner, placed in a distance of $1200 \mathrm{~mm}$ from the sample. An extra slit was inserted between the sample and the detector, which implied that only the (111) and (200) DebyeScherrer rings were visible on the detector. The slit served to reduce the background level from stray scattering in the experimental 


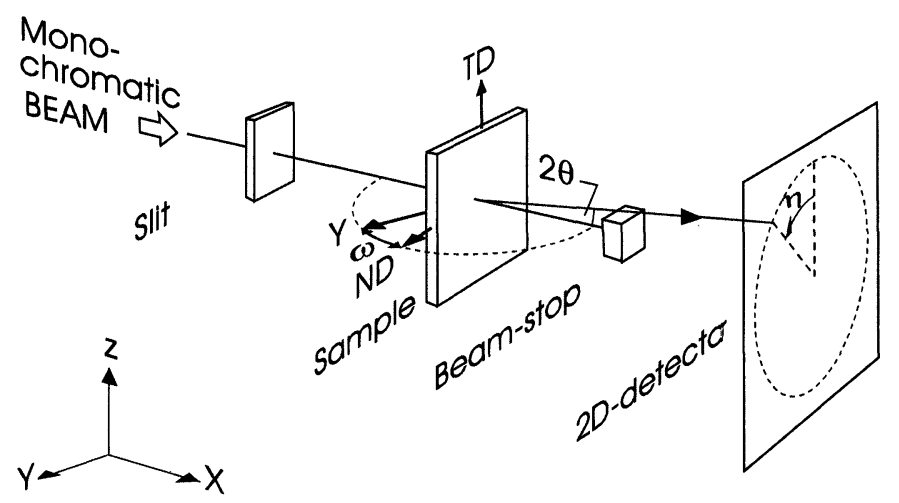

FIGURE 2 Sketch of texture set-up at the BW5 beamline at HASYLAB. The angles $2 \theta, \eta$ and $\omega$ are defined.

hutch. As a result, the background was determined not by the instrument but by the incoherent scattering of the sample.

Partial pole figures were obtained by the rotation method discussed in the paper by Mishin et al., 2000. Diffraction images were acquired for a series of equiangular $\omega$-settings ranging from $-44^{\circ}$ to $44^{\circ}$ with a stepsize of $\Delta \omega=2^{\circ}$. During each exposure the rotation table was oscillated through a range of $\Delta \omega= \pm 1^{\circ}$ around the nominal $\omega$-position, in order to sample the pole figure evenly. Two pole figures were determined in order to enhance the effective dynamic range of the detector (the pixel capacity saturates at a level of around 250,000 counts/pixel utilizing the $18 \mathrm{bits} /$ pixel architecture). The first one was determined with exposure times of $30 \mathrm{~s}$ and no absorber. In the second run the exposure time was $2 \mathrm{~s}$ and a $10 \mathrm{~mm}$ thick Fe absorber was inserted into the incident beam. The latter data set was scaled and combined with the former to provide valid data on both the high and low intensity parts of the pole figure. Erasure times between two successive exposures were proven to be sufficiently long to prevent the appearance of "ghosts" in the images.

The initial data analysis was performed using the program FIT2D (Hammersley et al., 1996). For each image the integrated intensity within a small radial interval around the (111)-ring was determined as a function of the azimuthal co-ordinate $\eta$ as defined in Fig. 2. A background value based on the intensity in neighboring radial intervals was subtracted. An example of the intensity variation with $\eta$ is given in 


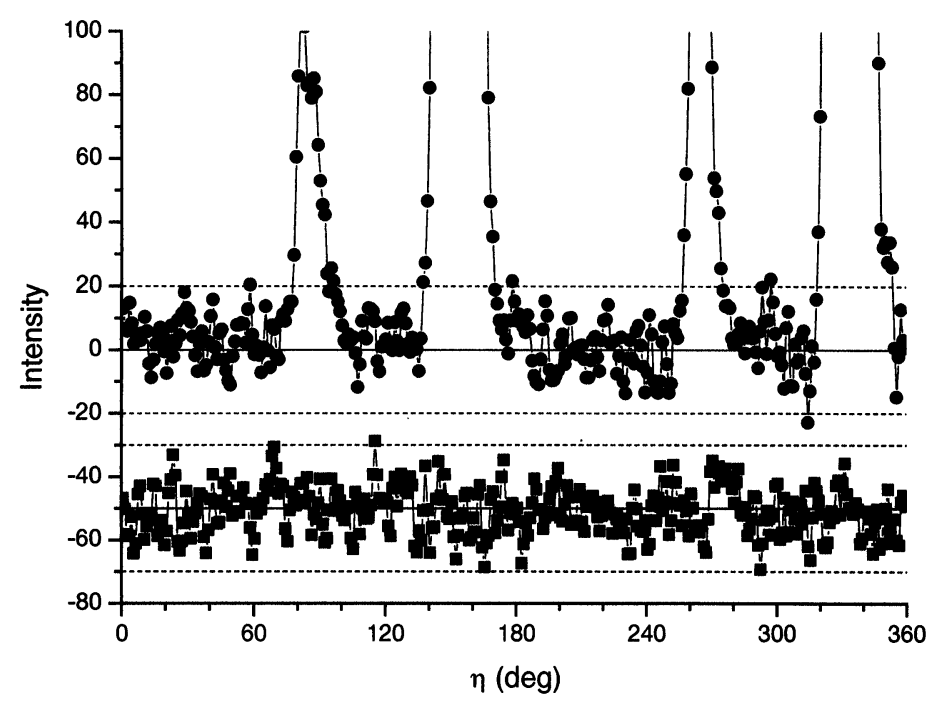

FIGURE 3 The azimuthal $(\eta)$ variation of the intensity in the (111) ring for $\omega=1^{\circ}$. Background subtracted data are shown for $30 \mathrm{~s}$ exposures with sample $(\bullet)$, and without sample ( $\mathbf{\square})$. The latter data set is shifted by -50 counts to ease the presentation.

Fig. 3. The figure also contains the result for an acquisition performed with no sample. From this we estimate the noise-level to be 20 counts. In comparison the major poles in the pole figure were found to have peak intensities of the order 600,000 counts (and FWHM widths of $7^{\circ}$ along both the $\omega$ and $\eta$ co-ordinate).

The intensity $I(i)$ of any point $i$ in the pole figure was interpolated from the measured intensities $I(j)$ by assigning weights to each measured point $j$ on the pole sphere. The weights, $W(i, j)$, were determined using the Watson distribution, which is the closest equivalent on the unit sphere to a Gaussian distribution (Fisher et al., 1987)

$$
I(i)=\sum I(j) W(i, j)=\frac{1}{C} \sum_{j} I(j) \exp \left(k\left(\left(\bar{G}_{i} \cdot \bar{G}_{j}\right)^{2}-1\right)\right)
$$

Here $\bar{G}_{i}$ and $\bar{G}_{j}$ are the unit vectors. The degree of smoothing was controlled by the concentration parameter $k$ of this distribution, which was set to give a standard deviation on the rotation angle of $2^{\circ}$. The resulting pole figure is plotted in Fig. 4, with the minimum contour line set at the noise level of 20 counts. 


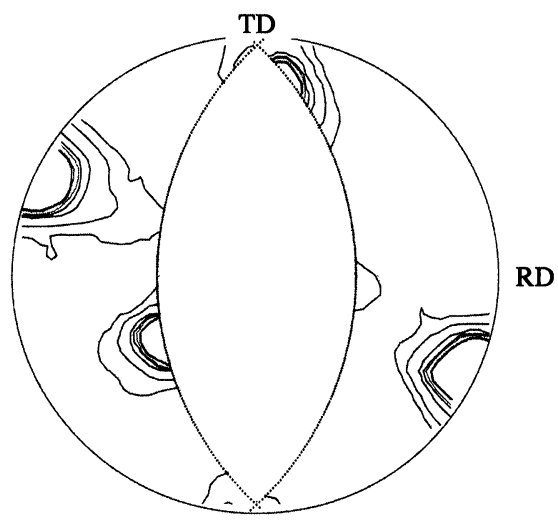

FIGURE 4 The incomplete (111) pole figure determined with hard X-rays by probing a volume of $3 \mathrm{~mm}^{3}$. The central part, which for time reasons was not measured, is marked. The contour levels are: $20,100,1000,3000$, and 5000, respectively. The maximum intensity of the poles is about 600,000 .

Based on Fig. 4, as well as manual inspection of the individual data sets of the type shown in Fig. 3, no trace of intensity outside the main poles was found. Hence, far from the poles the volume fraction $V_{V}$ of deformed material is below a certain threshold. Neglecting a minor geometric factor related to the spherical projection, this threshold is given by

$$
V_{V}=\frac{m}{2} \frac{I}{I_{\mathrm{tot}}}
$$

Here $I$ is the integrated intensity within an area of interest in the pole figure, and $I_{\text {tot }}$ is the integrated intensity over the whole pole figure. The term $m$ is the multiplicity of the reflection (i.e. 8 for 111). For a feature in the pole figure with a width given by the sampling of the pole figure $\left(2^{\circ}\right)$ and a peak intensity equal to the noise limit of 20 counts, we find a limiting volume fraction of $V_{V}=5 \times 10^{-6}$.

\section{HIGH RESOLUTION HARD X-RAY POLE FIGURE}

The second experiment took place at the 3DXRD microscope, installed at the Materials Science Beamline ID11 at ESRF. The microscope, which was commissioned in 1999; is dedicated to 3D 
micron-scale structural characterization within bulk specimens (Poulsen et al., 1997, Lienert et al., 1999, Juul Jensen et al., 2000, Nielsen et al., 2000a, Lauridsen et al., 2001, Poulsen et al., 2001). The incoming beam was monochromatized at $50 \mathrm{keV}(\lambda=0.248 \AA)$ and focused in the vertical direction by a bent $\mathrm{Si}$ (111) crystal. The width of the focus was $8 \mu \mathrm{m}$ (FWHM). Horizontally, the beam was defined by a slit to $10 \mu \mathrm{m}$. With a monochromator-to-sample distance of $2 \mathrm{~m}$, the divergence of the monochromatic beam was $0.4 \mathrm{mrad}$.

The sample was placed in the focal spot, mounted on a horizontal rotation table ( $\omega$ - rotation) with TD along the $\omega$-axis and ND parallel to the beam for $\omega=0^{\circ}$. The diffracted beam transmitted through the sample with $30 \%$ absorption, as the penetration depth in aluminum is $10 \mathrm{~mm}$ at $50 \mathrm{keV}$. The detector was an image intensifier coupled to a FRELON CCD camera. This two-dimensional detector exhibits anti-blooming and a high photon sensitivity. The innermost 5 DebyeScherrer rings were registered in this way.

The experiment focused on the characterization of a $900 \mu \mathrm{m}$ broad stripe, placed at the center line of the sample, see Fig. 5. The sample was translated in the $y$ direction within the range of the stripe in steps of $10 \mu \mathrm{m}$. For each $y$-setting data acquisitions were performed for $\omega$-settings of $-30^{\circ},-25^{\circ},-20^{\circ},-15^{\circ}$ and $-10^{\circ}$. As illustrated in Fig. 5 the different $\omega$-settings probe different parts of the sample for

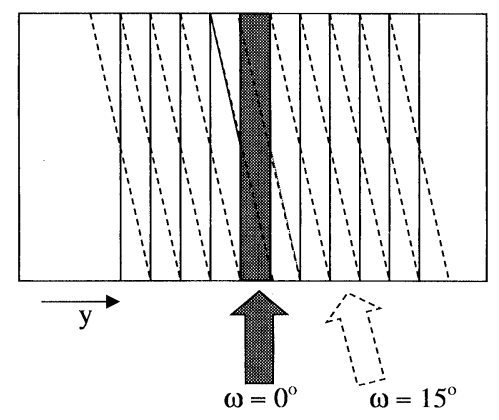

FIGURE 5 The principle of the high resolution hard X-ray method. At an angular setting of $\omega=0^{\circ}$ the incident beam illuminates a narrow channel through the thickness of the sample (hatched area). Images are acquired while scanning the sample in the $y$ direction with a step size identical to the size of the beam. This procedure is repeated at a number of $\omega$-settings, illustrated here by $\omega=15^{\circ}$. It is seen that in the central part the layer is probed homogeneously both spatially and with respect to angle. 


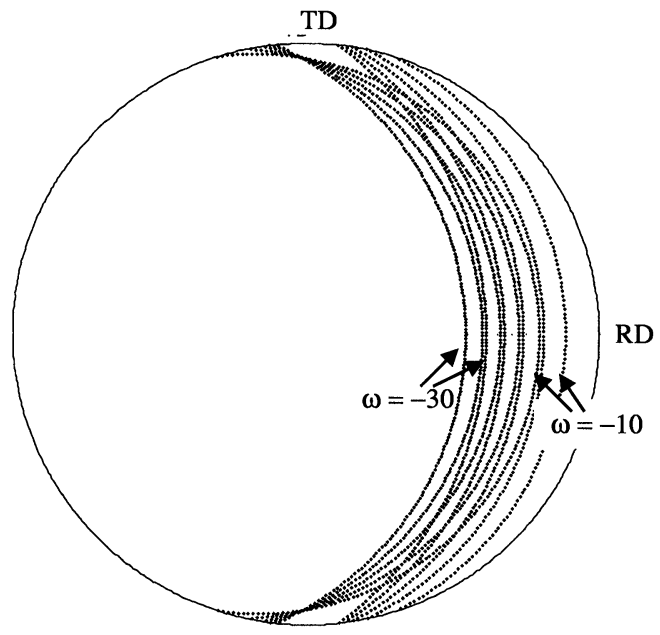

FIGURE 6 Parts of a polefigure determined by the $5 \omega$-settings used for the high resolution hard X-rays experiment. Each setting is associated with two curves, both with a width of $1^{\circ}$. The $\omega=-10^{\circ}$ and $-30^{\circ}$ curves are marked.

fixed $y$, but the scan over $y$ implies that the full stripe is probed at all 5 angles. During exposures, which took $15 \mathrm{~s}$ each, the sample was oscillated by $1^{\circ}$ in $\omega$. The parts of the RD-TD pole figure probed in this way are shown in Fig. 6.

In addition, two complete pole figures were determined at the midpoint in the $y$ range. One with an exposure time of $15 \mathrm{~s}$ and one with an exposure time of $0.1 \mathrm{~s}$ and an added absorber. Comparing the two, the intensities of the poles and the background level were scaled analogously to the HASYLAB case. The total beamtime spent for measurements was $5 \mathrm{~h}$.

The data analysis was similar to the HASYLAB case. The pole figure based on the attenuated beam data is shown in Fig. 7. The large-scale features are seen to be similar to the EBSP and HASYLAB data sets in Fig. 1 and Fig. 4 respectively. For the non-attenuated beam data set, examples of the background corrected data are given in Fig. 8. The noise-level is estimated to be \pm 20 counts. In comparison the major poles had scaled peak intensities of $2 \times 10^{6}$ counts (and FWHM widths of $7^{\circ}$ along both $\omega$ and $\eta$ ).

As evidenced by Fig. 8 for a few $y$-positions distinct spikes were found at large angles to the poles. These typically had a peak intensity 


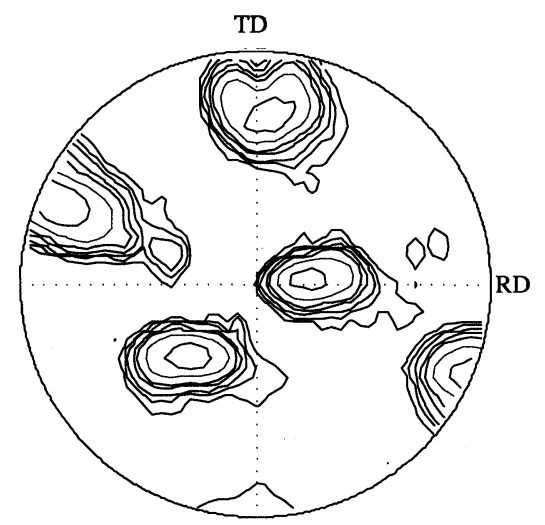

FIGURE 7 A (111) pole figure of the deformed Al single crystal obtained with the 3DXRD microscope without scanning. The major texture components are shown with contour levels of 5,20,50,200,500,2000, and 5000, respectively. A beam absorber was inserted in the incident beam to avoid detector saturation.

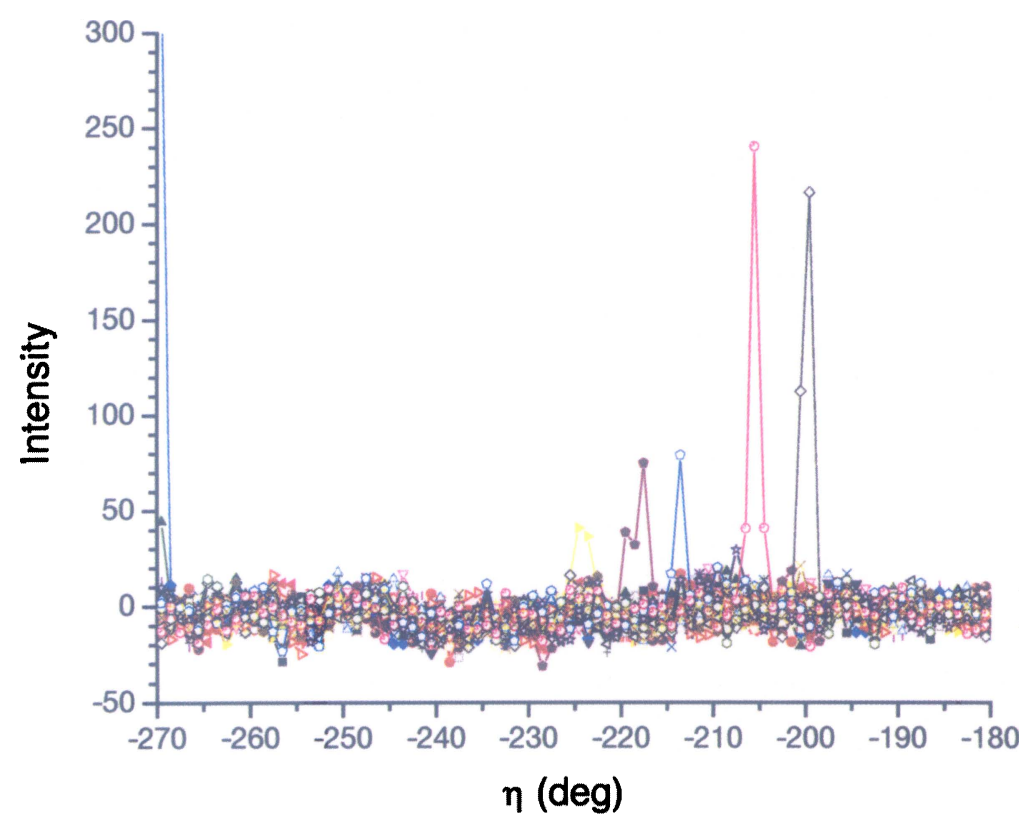

FIGURE 8 Example of background subtracted data extracted by means of the high resolution method at the 3DXRD microscope at ESRF. The azimuthal $(\eta)$ variation of the intensity in the (111) ring at $\omega=-30^{\circ}$ is shown for $30 y$ positions. The 30 scans -identified by different symbols and colors - are overlaid. The spikes in the spectrum are identified as arising from individual dislocation cells. (see colour plate at the back of this issue). 
of 100 counts and a width of $1^{\circ}$ in $\eta$. The spikes are identified as individual cells in the microstructure on several grounds. Firstly, by inspection the spikes were found to be distinct in the original 2D images and positioned with the correct $2 \theta$ angle. No "negative spikes" were observed, as would have been the case if their origin were random noise (the spikes would then also appear in the $2 \theta$ bands used for background subtraction). Secondly, higher harmonics are not a concern. X-rays with energies of 3 times $50 \mathrm{keV}$ also emerge from the monochromator, but at much reduced intensities. This implies that $150 \mathrm{keV}$ (511) and (333) reflections can appear at the same Bragg angle as the $50 \mathrm{keV}$ (111) reflection. Similarly the third harmonics (600) and (422) can appear at the same $2 \theta$ as the fundamental (200) reflection. However, we can rule out the (511) and (422) cases as no spikes are found at the position where these reflections should give rise to poles. Furthermore it doesn't matter whether we are observing spikes from the (111) or (333) reflection, as the resulting pole figures by definition are the same. The same argument can be used for (200) and (600). Thirdly, based on intensity considerations of the type given in Eq. (2) the volume fraction associated with such a spike is estimated to be $V_{V}=1 \times 10^{-6}$. With a gauge volume of $8 \times 10 \times 1200 \mu \mathrm{m}^{3}$ this implies a volume of $0.12 \mu \mathrm{m}^{3}$. As part of the integrated intensity on average will be lost, as it resides in neighboring $\omega$-ranges, this number is in reasonable accordance with the average cell size of $0.5 \mu \mathrm{m}^{3}$. Finally, some spatial correlations between spikes were observed, reminiscent of the behavior of cell blocks.

Figure 9 is a plot of the orientation of the spikes identified far from the poles within one quarter of the pole figure. No specific clustering of spikes is found, instead they seem to cover the entire pole figure. Upon summing the $90 \eta$-sections for each $\omega$-setting the spikes disappeared in the noise, effectively re-establishing the result from the experiment at HASYLAB.

\section{DISCUSSION}

The pertinent features of the 3 measuring techniques applied are summarised in Table I. EBSP is seen to have a medium spatial resolving power - identical to its spatial resolution - while the probe 


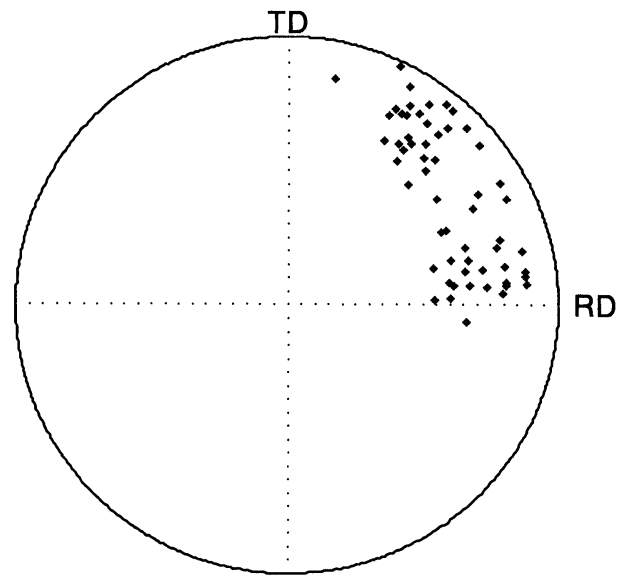

FIGURE 9 Result of the high resolution hard X-ray method. The position of the spikes identified far from the poles is shown for one quarter of the (111) pole figure of the deformed $\mathrm{Al}$ single-crystal sample.

TABLE I Comparison of the three methods used for texture characterization. The $\omega$-range used for the two hard X-ray methods implied that only partial pole figures were determined, cf. Figs. 4 and 6

\begin{tabular}{lcccc}
\hline & $\begin{array}{c}\text { Resolving } \\
\text { power }\left(\mu \mathrm{m}^{3}\right)\end{array}$ & $\begin{array}{c}\text { Probe } \\
\text { volume }\left(\mu \mathrm{m}^{3}\right)\end{array}$ & $\begin{array}{c}\text { Volume } \\
\text { fraction }\end{array}$ & $\begin{array}{c}\text { Acquisition } \\
\text { time }(\mathrm{h})\end{array}$ \\
\hline EBSP & 1 & $1.7 \times 10^{4}$ & $6 \times 10^{-5}$ & 12 \\
$\begin{array}{l}\text { Standard hard } \\
\text { X-ray pole figure }\end{array}$ & $1.5 \times 10^{4}$ & $4 \times 10^{9}$ & $5 \times 10^{-6}$ & 2 \\
$\begin{array}{l}\text { High resolution hard } \\
\text { X-ray pole figure }\end{array}$ & 0.03 & $9 \times 10^{6}$ & $3 \times 10^{-9}$ & 4 \\
\hline
\end{tabular}

volume is limited by the speed of data acquisition. (The acquisition time listed in Table I can be reduced by a factor of 10 using more advanced scanning procedures.) In contrast, generation of standard pole figures by hard X-ray synchrotron radiation is a very fast method, which can provide information averaged over large volumes. (Again, the acquisition time can be decreased by a factor of 10 by the use of a more sensitive 2D detector with a faster read-out, such as the image intensifier.) The volume fraction probed is intrinsically limited by the incoherent scattering. However, the number is sufficiently small that the method should be of general relevance for studies of minor texture components - and in particular their dynamics. 
The high resolution hard X-ray method has superior characteristics both in terms of resolving power and volume fraction. The main limitation is the speed of data acquisition. It can be mentioned that the 3DXRD microscope can be operated in another mode, where the incoming beam is focused in both the horizontal and the vertical direction. Assuming an optical configuration with two multilayers is used (Kirkpartick-Baez configuration) the intensity of the incoming beam is a factor of 100 times larger. Hence, the data acquisition time can be reduced, or alternatively the resolving power of the instrument can be made even smaller, of the order $10^{-2}-10^{-3} \mu \mathrm{m}^{3}$.

As another extension of the method we mention that we recently have established a general-purpose indexing program for polycrystals, GRAINDEX (Lauridsen et al., 2001). Provided the $\omega$-range is not too small this should make it possible to determine both the full orientation and the position of the cells or subgrains, provided that they have nonoverlapping diffraction spots.

In outlook, the high resolution method is of relevance for in situ nucleation studies of coarse-grained polycrystals. In this case we suggest inserting a conical slit between the sample and the detector. Such slits have conical openings along a set of Debye-Scherrer rings and serve to define an intrinsic "volume of interest" within the sample (Nielsen et al., 2000b). Hence, provided the grains are sufficiently big the "single-crystal situation" with no overlapping diffraction spots from neighbours is re-established. At present conical slits have been manufactured with a slit gap of $20 \mu \mathrm{m}$.

Another possible application of the high resolution hard X-ray method is for structural identification, location and texture analysis of very dilute crystalline precipitates with a particle size of order $0.1-1 \mu \mathrm{m}$.

\section{Acknowledgements}

We thank J. Driver for providing the Al single-crystal sample, A. Abrahamsen for help with the experiment at HASYLAB, and P. Olesen and N.C. Krieger Lassen for help with analyzing the EBSP data. This work was supported by the Danish Natural Science Research Council via Dansync. 


\section{References}

Beck, P. and Sperry, P.R. (1950). Strain induced boundary migration in high purity aluminium. Journal of Applied Physics, 21, 150-152.

Bouchard, R., Hupfeld, D., Lippmann, T., Neuefeind, J., Neumann, H.-B., Poulsen, H.F., Rütt, U., Schmidt, T., Schneider, J.R., Sussenbach, J. and von Zimmermann, M. (1998). A triple-crystal diffractometer for high-energy synchrotron radiation at the HASYLAB high-filed wiggler beamline BW5. Journal of Synchrotron Radiation, 5, 90-101.

Dillamore, I.L., Morris, P.L., Smith, C.J.E. and Hutchinson, W.B. (1972). Transition bands and recrystallization in metals. Proceeding of Royal Society, London, 329A, 405-420.

Doherty, R.D., Samajdar, I., Necker, C.T., Vatne, H.E. and Nes, E. (1995). Nucleation of recrystallization in cold and hot deformed polycrystals. In: Hansen, N., Juul Jensen, D., Liu, Y.L., and Ralph, B. (Eds.), Proceedings 16th Risø International Symposium on Materials Science: Microstructural and Crystallographic Aspects of Recrystallization, pp. 1-23. Risø, Denmark.

Fischer, N.I., Lewis, T. and Embleton, B.J.J. (1987). Statistical Analysis of Spherical Data. Cambridge Univ. Press, Cambridge.

Godfrey, A., Juul Jensen, D. and Hansen, N. (1995). Influence of localized glide on the recrystallization of a channel die deformed (211) $\langle 111\rangle$ orientation aluminium single crystal. In: Hansen, N., Juul Jensen, D., Liu, Y.L., and Ralph, B. (Eds.), Proc. 16th Riso International Symposium on Materials Science: Microstructural and Crystallographic Aspects of Recrystallization. pp. 365-370, Risø, Denmark.

Godfrey, A., Juul Jensen, D. and Hansen, N. (2001). Recystallization of Channel Die Deformed Single Crystals of Typical Rolling Orientations. Acta Materialia, in press.

Hammersley, A.P., Svensson, S.O., Hanfland, M., Fitch, A.N. and Häusermann, D. (1996). Two-dimensional detector software: From real detector to idealised image or two-theta scan. High Pressure Research, 14(4-6), 235-248.

$\mathrm{Hu}, \mathrm{H}$. (1963). Annealing of Silicon-Iron Crystals. In: Himmel, H. (Ed.), Recovery and Recrystallization of Metals. pp. 311-362. AIME Interscience, New York.

Huang, X., Wert, J.A., Poulsen, H.F., Krieger Lassen N.C. and Inoko, F. (2000) Characterization of deformation structure and recrystallization in a tensile deformed [110] aluminum single crystal. In: Hansen, N. et al. (Eds.), Proc. 21st Risø International Symposium on Materials Science: Recrystallization-Fundamental Aspects and Relations to Deformation Microstructure. pp. 359-364, Risø, Denmark.

Humphreys, F.J. and Hatherly, M. (1995). Recrystallization and Related Annealing Phenomena. Perganon Press, Oxford.

Humphreys, F.J. (1997). A Network Model for Recovery and Recrystallization. Acta Materialia, 45, 4231-4240.

Humphreys, F.J. and Brough, I. (1999). EBSD with FEGSEM - Issues, Advances and Applications. Microscopy and Microanalysis, 5, 240-241.

Inoko, F., Okada, T., Tagami, M. and Kashihara, K. (1995). Relations between deformed microstructures and $\langle 111\rangle \quad(\mathrm{FCC})$ and $\langle 011\rangle$ (BCC) rotation recrystallization mechanisms. In: Hansen, N., Juul Jensen, D., Liu, Y.L., and Ralph, B. (Ed.), Proc. 16th Risø International Symposium on Materials Science: Microstructural and Crystallographic Aspects of Recrystallization. pp. 375-380, Risø, Denmark.

Juul Jensen, D., Kvick, Å., Lauridsen, E.M., Lienert, U., Margulies, L., Nielsen, S.F. and Poulsen, H.F. (2000). Plastic deformation and recrystallization studied by the 3D X-ray microscope. Materials Research Society Symposium Proc., 590, $227-240$.

Juul Jensen, D. (2000). Deformation and recrystallization studied by EBSP: breakthroughs and limitations. Materials Science and Technology, 16, 1360-1363. 
Kamijo, T., Katao, S. and Inagaki, H. (1993). Nucleation and growth of cube-oriented recrystallized grains in an aluminium single-crystal of an S-orientation. Acta Metallurgica and Materialia, 41, 1713-1720.

Kashiara, K.,Tagami, M. and Inoko, F. (1996). Recrystallization behaviour at deformation at deformation bands in $\langle 011\rangle$ aluminium single crystals. Materials Transactions JIM, 37, 572-578.

Keitel, S., Retsch, C.C., Niemöller, T., Schneider, J.R., Rossolenko S.N. and Riemann, H. (1998). $\mathrm{Si}_{1-\mathrm{x}} \mathrm{Ge}_{\mathrm{x}}$ gradient crystals: A new monochromator material for hard Xrays. Nuclear Instruments and Methods A, 414(2-3), 427-430.

Kikuchi, S., Kimura, E. and Koiwa, M.(1992). Deformation and recrystallization textures of copper single-crystals and bicrystals. Journal of Materials Science, 27, 4927-4934.

Krieger Lassen, N.C., Juul Jensen, D. and Conradsen, K. (1992). Image Processing Procedures for Analysis of EBSPs. Scanning Microscopy, 6, 115-121.

Lauridsen, E.M., Schmidt, S., Suter, R.M. and Poulsen, H.F. (2001). Tracking: a method for structural characterization of grains in powders or polycrystals. Journal of Applied Crystallography, (in print).

Lienert, U., Poulsen, H.F. and Kvick, A (1999). Proc. 40th Conf. of AIAA on Structures, Structural Dynamics and Materials, St. Louis (USA), 2067-2075.

Mishin, O.V., Lauridsen, E.M., Krieger Lassen, N.C., Brückner, G., Tschentscher, T., Bay, B., Juul Jensen, D. and Poulsen, H.F. (2000). Application of high-energy synchrotron radiation for texture studies. Journal of Applied Crystallography, 33, 364-371.

Nielsen, S.F., Ludwig, W., Bellet, D., Lauridsen, E.M., Poulsen, H.F. and Juul Jensen, D. (2000a). Three dimensional mapping of grain boundaries. In: Hansen, N., Huang, X., Juul Jensen, D., Lauridsen, E.M., Leffers, T., Pantleon, W., Sabin, T.J. and Wert, J.A. (Eds.) Proc. 21st Risø International Symposium on Materials Science. Roskilde, pp. 473-478.

Nielsen, S.F., Wolf, A., Poulsen, H.F., Ohler, M., Lienert, U. and Owen, R.A. (2000b). A conical slit for three-dimensional XRD mapping. Journal of Synchrotron Radiation, 7, 103-109.

Orlans-Joliet, B., Driver, J.H. and Montheillet, F. (1990). Plane-strain compression of silicon-iron single-crystals. Acta Metallurgica et Materialia, 38(4), 581-594.

Poulsen, H.F., Garbe, S., Lorentzen, T., Juul Jensen, D., Poulsen, F.W., Andersen, N.H., Frello, T., Feidenhans'l, R. and Graafsma, H. (1997). Application of highenergy synchrotron radiation for structural studies of polycrystalline materials. Journal of Synchrotron Radiation, 4, 147-154.

Poulsen, H.F., Frello, T., Andersen, N.H., Bentzon, M.D. and von Zimmermann, M. (1998). Structural studies of BSCCO/Ag-tapes by high-energy synchrotron X-ray diffraction. Physica C, 298, 265-278.

Poulsen, H.F., Nielsen, S.F., Lauridsen, E.M., Schmidt, S., Lienert, U., Suter, R.M., Margulies, L., Lorentzen, T. and Juul Jensen, D. (2001). Three-dimensional maps of grain boundaries and the stress-state of individual grains. Submitted for publication.

Wcislak, L., Klein, H., Bunge, H.J., Garbe, U., Tschentscher, T. and Schneider, J.R. (2001). Texture analysis with high-energy synchrotron radiation. Submitted for publication.

Zaefferer, S., Baudin, T. and Penelle, R. (2001). A study of the formation mechanisms of the cube recrystallization texture in cold rolled Fe-36\%Ni alloys. Acta Materialia, 49, $1105-1122$. 